\title{
A particularidade da dimensão investigativa na formação e prática profissional do assistente social
}

\section{The peculiarity of the investigative dimension in the social worker's formation and professional practice}

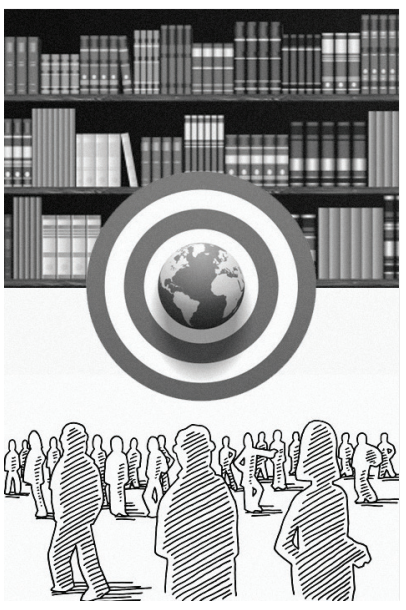

\section{Carlos Antonio de Souza Moraes*}

Resumo: O artigo problematiza "como" a dimensão investigativa tem sido construída nos cursos de graduação em Serviço Social na atualidade, bem como se os discursos críticos vinculados à investigação e edificados na academia têm conseguido alimentar a ação profissional. Para tanto, recorre à pesquisa bibliográfica e de campo. Os resultados preliminares indicam que a precarização do ensino superior, da formação profissional, das condições de trabalho docente e do assistente social, bem como sua condição assalariada e o compromisso com a qualidade dos serviços e com a formação intelectual são centrais para análise do tema.

Palavras-chave: Serviço Social. Formação profissional. Prática profissional. Dimensão investigativa.

\begin{abstract}
The article brings forward two questions: "how" the investigative dimension has been built up in the graduation courses of Social Work nowadays, and "if" the critical discourses that are linked to investigation and built up in the university can foster the professional action. To do so, both bibliography and field research were undertaken. The preliminary results show that the precariousness of university courses, professional formation, teaching conditions, social workers' working conditions, as well as their salaried condition and the commitment with the quality of the work and the intellectual formation are central to the analysis of the theme.
\end{abstract}

Keywords: Social Work. Professional formation. Professional practice. Investigative dimension.

* Bacharel em Serviço Social pela UFF/Campos (RJ), mestre em Políticas Sociais pela Uenf, doutorando em Serviço Social pela PUC-SP, professor assistente na Universidade Federal Fluminense, Rio de Janeiro (RJ), Brasil, pesquisador do Grupo Interdisciplinar de Estudos e Pesquisa em Cotidiano e Saúde (Gripes). E-mail: as.carlosmoraes@gmail.com. 


\section{Reflexões introdutórias}

Desconfiai do mais trivial, na aparência singelo. E examinai, sobretudo, o que parece habitual. Suplicamos expressamente: não aceiteis o que é de hábito como coisa natural, pois em tempo de desordem sangrenta, de confusão organizada, de arbitrariedade consciente, de humanidade desumanizada, nada deve parecer natural, nada deve parecer impossível de mudar. Bertolt Brecht.

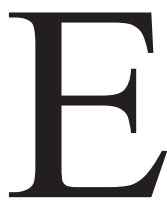

ntre assistentes sociais ainda circulam algumas compreensões do “estágio supervisionado em Serviço Social como 'treino’ da prática profissional" e de que "na prática a teoria é outra", portanto, "muitas vezes, é preciso esquecer o que se aprendeu na academia para sobreviver enquanto trabalhador assalariado, inserido no mercado de trabalho através de contratos de trabalho precarizados".

Não por acaso, as principais análises teóricas referentes ao trabalho/exercício/prática ${ }^{1}$ profissional ainda tem identificado o assistente social como o profissional que "faz tudo", priorizando requisições e interesses institucionais, colocando-se como aquele que, embora tenha um discurso que, aparentemente, se aproxima dos usuários, na prática se distancia ao tentar manter a ordem e o controle institucionais, reproduzindo práticas imediatas, gestadas e determinadas pela instituição empregadora.

A esse respeito, a hipótese de Vasconcelos (2010-2011, p. 11) é de que

no que se refere à prática direta com os usuários, é quase nula a diferença que separa o presente do passado na prática do Serviço Social no país, com a maioria dos assistentes sociais priorizando as requisições, interesses institucionais e consentindo, ainda que seja um consentimento não intencionado — que, na atenção aos usuários, impere formas históricas de mando e obediência, ainda que reatualizadas e/ou "resignificadas".

1. Este artigo aborda prática profissional, exercício profissional e trabalho profissional como sinônimos, ao compreendê-los tendo por base as dimensões da competência profissional. Isto é, defendemos que a definição desses conceitos é, necessariamente, constituída pelas dimensões teórico-metodológica, ético-política e técnico-operativa. Para aprofundar a discussão, ver Moraes, 2014. 
$\mathrm{Na}$ tentativa de, conforme sugerido por Brecht, desconfiar, examinar e analisar essa situação presente no interior do Serviço Social, a Associação Brasileira de Ensino e Pesquisa em Serviço Social (Abepss) e demais intelectuais dessa área de conhecimento têm defendido veementemente que o debate da prática/exercício/trabalho profissional não pode ser desvinculado do debate da formação profissional e nem o contrário.

No que se refere à formação profissional, é consenso entre os autores que têm se debruçado sobre o tema que temos sofrido diretamente com a expansão da política de educação do ensino superior através de uma larga escala de expansão universitária mercantil, que aprofunda a privatização interna das universidades públicas e amplia a privatização da educação superior presencial e à distância (Dahmer, 2008), contribuindo para omitir a intensificação da desqualificação da formação profissional, sob aparência de ampliação do acesso ao "ensino" superior (Lima, 2008).

Mota (2011), ao analisar as atuais tendências da política de educação superior entre 2000 e 2010, indica que há a adoção, pelo governo Lula, de uma pedagogia que tem a capacidade de obter consensos junto à sociedade, posto que era permeada de apelos populistas e de usos transformistas de conceitos e reivindicações que foram tecidos no campo da esquerda combativa e dos trabalhadores organizados. Para a autora, houve atendimento de algumas demandas processadas no campo da esquerda, mas destituídas de sua base original. São exemplos:

[...] o direito à educação, transformado em acesso aos serviços educacionais através do mercado; a ampliação de vagas atendida através da expansão de instituições privadas mercantis e do ensino à distância; a qualidade do ensino que passa a ser tratada como uma questão de eficiência e eficácia; a relação entre público e privado como esferas complementares. Além disso, procuraram suprimir as tensões e os projetos de uma formação superior laica, pública e socialmente referenciada através do marketing social, via política de cotas, financiamento das mensalidades do ensino privado e da abertura desmedida de novos cursos, através do Reuni e da interiorização de novas Instituições de Ensino Superior (IES). (Mota, 2011, p. 60-61)

No que se refere ao governo Dilma Rousseff, dados recentes indicam que essa política continua em curso, quando as autorizações para funcionamento já 
chegam a 567 cursos aprovados pelo MEC (embora nem todos estejam em funcionamento) (Abreu, 2013).

Esses dados possibilitam recorrer a Mészáros (2005) ao afirmar que a educação tem se evidenciado como elemento preponderante para a efetivação do capital, a ampliação do processo de superexploração do trabalho, promovida pela reestruturação produtiva, que tem o objetivo de transformar os processos de produção, circulação e consumo de mercadorias, mais ágeis e intensivos.

Nesse contexto, a educação configura-se como estratégia de manutenção da hegemonia do capital, frente à crise de acumulação. Como política e como direito social, suas medidas têm sido cada vez mais regressivas, sendo ofertada de maneira minimalista para aumentar timidamente os salários e dinamizar o mercado de consumo. Marcas da mercantilização se fazem presentes em todos os níveis educacionais, em especial no ensino superior (Pereira e Almeida, 2012).

Diante disso, é possível afirmar que a contrarreforma do ensino superior no Brasil é questão central para o Serviço Social, já que o crescimento mercantil das vagas em cursos privados e na modalidade à distância pode redefinir, em curto prazo, o perfil profissional, pronto a atender acriticamente as demandas imediatas do capital, formando um exército social de reserva (Iamamoto, 2008). Assim, a defesa do projeto de formação profissional construído e explicitado nas Diretrizes Curriculares da Abepss de 1996 tem se colocado como inadiável para o Serviço Social, pois desta tarefa também imprescinde a reafirmação do projeto ético-político profissional, que tem como um dos seus componentes centrais a formação profissional.

Em termos quantitativos, o Serviço Social brasileiro, no ano de 2011, possuía 358 cursos de graduação autorizados pelo Ministério da Educação (MEC), sendo 340 de ensino presencial e dezoito do ensino à distância. No entanto, os cursos de ensino à distância ofertaram, no ano de 2011, 68.742 vagas, enquanto o ensino presencial ofertou 39.290 (Iamamoto, 2014, informação verbal).

Isto demonstra que os dezoito cursos de ensino à distância ofertaram, no período de 2011, quase o dobro dos 340 cursos presenciais. A esse quadro alia-se o quantitativo de assistentes sociais ativos no Brasil. Segundo o Conselho Federal de Serviço Social (CFESS, 2013), temos 135 mil profissionais, sendo 
o segundo país no mundo com maior contingente profissional (Iamamoto, 2014, informação verbal).

Mediante a concepção de educação "acrítica" e os dados ora apresentados, torna-se possível evidenciar as seguintes questões em confronto com o projeto de formação profissional do Serviço Social atual: privatização do ensino superior; crescimento do ensino à distância; precarização das condições de trabalho e do trabalho docente; exacerbado produtivismo acadêmico; adoecimento de docentes e discentes como fruto destes processos; aumento de vagas para uma formação rápida; baixa qualidade da educação; falta de incentivo e condições de construção de propostas de pesquisa e extensão articuladas ao ensino; compreensão do estágio supervisionado em Serviço Social como "treino" da prática profissional, sem articulação entre seus supervisores, mediante número excessivo de demandas e problemas na captação de vagas de estágio.

Além desses fatores, Iamamoto (2014) acrescenta a ampliação do acesso da juventude trabalhadora ao ensino superior, através de financiamento do Estado ao empresariado da educação. Para autora, a busca pelo ensino superior está vinculada a ascensão social e elevação de status no seio familiar. Ainda faz referência à influência da religiosidade, com destaque para o protestantismo, nos dias atuais (com a defesa da fraternidade e prosperidade econômica capitalista). Religiosidade amplamente afinada com a ascensão social nos moldes capitalistas (informação verbal).

Esses aspectos alteram a condição de classe do segmento profissional. Para Iamamoto (2014), há uma redução da distância social entre a categoria profissional e o público atendido, e essas transformações, que merecem ser estudadas e analisadas de forma cuidadosa, produzem implicações para o universo cultural dos estudantes.

Diante disso, torna-se possível afirmar que vivemos, na atualidade, um processo de precarização na formação de assistentes sociais, que incide na qualidade do ensino e no aligeiramento da pesquisa e da capacidade de construção do conhecimento de forma crítica e autônoma, além de maior preocupação com o treinamento dos graduandos, voltando-se para demandas flexíveis do mercado, que reforçam os mecanismos ideológicos de submissão dos profissionais, o que pode provocar um imenso processo de despolitização da categoria profissional (Iamamoto, 2014; informação verbal). 
Por outro lado, a categoria profissional tem se mobilizado na problematização, análise e debates referentes a esse modelo mercantil e privatizante e seus rebatimentos na formação dos assistentes sociais. Grande expressão desses debates é a campanha realizada pelo Conselho Federal de Serviço Social e Conselhos Regionais de Serviço Social, a Associação Brasileira de Ensino e Pesquisa em Serviço Social, e a Executiva Nacional de Estudantes de Serviço Social, denominada "Educação não é fast-food", que contou com o apoio do Andes - Sindicato Nacional dos Docentes das Instituições de Ensino Superior - e várias entidades de defesa da educação como direito. Além disso, essa problemática tem sido discutida nos encontros e congressos da categoria profissional, bem como tem sido alvo de debates nos cursos Abepss itinerante.

Ao particularizar a dimensão investigativa na formação e prática profissional do assistente social, tendo por base a compreensão e análise da política de educação do ensino superior no contexto atual e confrontando com a defesa do projeto de formação profissional do Serviço Social brasileiro contemporâneo, este artigo tem como proposta problematizar o "lugar" que a dimensão investigativa tem construído na formação e prática profissional do assistente social. Assim, objetiva compreender e analisar "como" essa dimensão tem sido construída e trabalhada nos cursos de graduação em Serviço Social na atualidade, bem como se os discursos críticos que tem se tentado edificar na academia (ainda que se considere os elementos analíticos anteriormente) conseguem alimentar as ações profissionais, tendo por objeto central a dimensão investigativa.

Para construção destas análises, partimos da compreensão e defesa de que as dimensões investigativa e interventiva devem ser estabelecidas "como princípios formativos e condição central da formação profissional e da relação teoria e realidade", defendendo, portanto, a unidade entre o pensar e o agir (Abepss, 1996, p. 6).

Neste sentido, há uma defesa da construção dessas problematizações tendo por base o legado do Movimento de Reconceituação do Serviço Social no Brasil e a construção de um novo projeto ético-político profissional. ${ }^{2}$ Entende

2. Este projeto tem em seu núcleo o reconhecimento da liberdade como valor central — a liberdade concebida historicamente, como possibilidade de escolha entre alternativas concretas; daí um compromisso com a autonomia, a emancipação e a plena expansão dos indivíduos sociais. Consequentemente, esse projeto 
que a defesa desse projeto de profissão pontua a necessidade de aproximação crítica com diversas temáticas ${ }^{3}$ vinculadas à formação e à prática profissional do assistente social.

Assim, reconhecemos, conforme analisa Mészáros (2005), o caráter dúbio da educação: como um dos momentos fundamentais da produção das condições objetivas de manutenção da ordem social do capital, pois é o meio pelo qual os indivíduos "internalizam" as perspectivas, os valores e a moral do sistema do capital, legitimando-a. Por outro lado, também é necessária para se pensar em uma estratégia de transição para outra forma de sociabilidade, que esteja para além do capital, sendo concebida como emancipadora.

Esse entendimento nos desafia a analisar a formação profissional do assistente social — particularizando a dimensão investigativa — determinada pelas engrenagens capitalistas atuais em confronto com um grupo de profissionais insistentes na resistência e crítica a esses processos e defensores do projeto de formação profissional atual.

Diante disso, o artigo é dividido em duas sessões. Na primeira, problematiza, a partir de entrevista realizada com a atual presidente da Abepss (gestão 2013-14), a dimensão investigativa na formação profissional do assistente social, a fim de discutir "onde" e "como" ela vem sendo trabalhada na graduação em Serviço Social. Nessa sessão, aponta três ângulos que precisam ser estudados e enfrentados no âmbito da formação profissional em Serviço Social. Na segunda sessão, constrói algumas reflexões referentes ao "lugar" que a dimensão investigativa tem assumido na prática profissional do assistente social. Tais reflexões são resultados preliminares de pesquisa realizada com assistentes sociais supervisores de estágio na área da saúde e cadastrados na Universidade Federal Fluminense em Campos dos Goytacazes (RJ). Tais profissionais realizam suas atividades nas regiões norte e noroeste fluminense. Os resultados analisados nesse item indicam que a precariedade do ensino superior e da

profissional se vincula a um projeto societário que propõe a construção de uma nova ordem social, sem exploração/dominação de classe, etnia e gênero. A partir dessas opções que o fundamentam, tal projeto afirma a defesa intransigente dos direitos humanos e o repúdio do arbítrio e dos preconceitos, contemplando positivamente o pluralismo, tanto na sociedade como no exercício profissional (Netto, 2005).

3. Que serão identificadas e problematizadas ao longo das duas sessões de discussão do tema. 
formação profissional, além das condições de trabalho - tipo de instituição, rotina e dinâmica de trabalho - , e o fato de ser trabalhador assalariado, bem como o compromisso com a qualidade dos serviços prestados e com o aprimoramento intelectual, tem sido determinantes da (não) construção da postura investigativa na prática profissional do assistente social.

\section{0 lugar da dimensão investigativa na formação profissional do assistente social}

Refletir acerca do lugar que a dimensão investigativa tem assumido na formação profissional tendo por base as Diretrizes Gerais para o Curso de Serviço Social (1996), significa tentar construir enfrentamentos, calcados pelos valores edificados a partir do Movimento de Reconceituação, via projeto ético-político profissional, que objetivem analisar as amarras arquitetadas pela contrarreforma do ensino superior no Brasil e tecer reflexões referentes a estratégias de confronto e superação.

Essa não é uma tarefa simples. Como vimos, a educação vinculada ao mercado, o aligeiramento da pesquisa e da descoberta científica na formação profissional, o treinamento dos graduandos e o reforço dos mecanismos ideológicos de submissão dos profissionais de Serviço Social, além da falta de condições de trabalho docentes, que tem contribuído para o processo de adoecimento dos mesmos, pode estar impulsionando a construção de um movimento de despolitização da categoria profissional.

Para enfrentar esse complexo quadro precisamos, a princípio, não nos rendermos exclusivamente à rotina das instituições acadêmicas, que, por conta de altos índices de produtividade, orientações de trabalhos, atividades administrativas e investimento pessoal no desenvolvimento de pesquisas, acabam esgotando, muitas vezes, as possibilidades de construção de análises e enfrentamentos coletivos (através da articulação com estudantes, docentes de outros departamentos, movimentos sociais, sindicatos da categoria etc.) referentes a esse processo de precarização do ensino superior e da atual concepção de educação disseminada pelo Estado. 
Ou seja, estamos tecendo considerações referentes a duas defesas complementares e indissolúveis. A primeira se vincula entre os atores da educação superior e seus posicionamentos e enfretamentos éticos e políticos no campo da sociedade, das instituições, da política e em sua relação com o Estado. A outra é referente aos atores da educação superior e a defesa do projeto de formação profissional no interior de suas instituições, se debruçando sobre estratégias que viabilizem a formação profissional em Serviço Social com base nas Diretrizes Gerais.

No que se refere mais especificamente à segunda defesa (não desconsiderando a unidade que possui com a primeira), compreendemos a necessidade de criação de espaços, ao longo da formação profissional, para o pensar crítico, para construção de debates, a exposição de dúvidas, através do estabelecimento das dimensões investigativa e interventiva como condição central de pensamento, crítica e abordagem do real (Abepss, 1996).

Neste sentido, há a defesa tanto da indissociabilidade entre ensino, pesquisa e extensão, quanto entre estágio, supervisão acadêmica e profissional, capazes de contribuir para a apreensão do significado social da profissão, das demandas, visando construir propostas de respostas profissionais que potenciem o enfrentamento da questão social, o que implica a capacitação teórico-metodológica, ético-política e técnico-operativa.

Ao longo das Diretrizes Gerais (1996), produto de um amplo e sistemático debate realizado pelas unidades de ensino a partir de 1994, é enfatizado a unidade entre o pensar e o agir.

Com base na análise do Serviço Social, historicamente construída e teoricamente fundada, é que se poderá discutir as estratégias e técnicas de intervenção a partir de quatro questões fundamentais: o que fazer, por que fazer, como fazer e para que fazer. Não se trata apenas da construção operacional do fazer (organização técnica do trabalho), mas, sobretudo, da dimensão intelectiva e ontológica do trabalho, considerando aquilo que é específico ao trabalho do assistente social em seu campo de intervenção. (Abepss, 1996, p. 14)

Diante disso, torna-se possível afirmar que, a partir de meados de 1990, a dimensão investigativa passou a ser requisitada com maior ênfase, como 
exigência para construção da prática profissional. A esse respeito, Guerra (2009, p. 712) destaca que

a investigação é inerente à natureza de grande parte das competências profissionais: compreender o significado social da profissão e de seu desenvolvimento histórico, identificar as demandas presentes na sociedade, realizar pesquisas que subsidiem a formulação de políticas e ações profissionais, realizar visitas, perícias técnicas, laudos, informações e pareceres sobre a matéria de Serviço Social, identificar recursos. Essas competências referem-se diretamente ao ato de investigar, de modo que, de postura a ser construída pela via da formação e capacitação profissional permanente (cuja importância é inquestionável), a investigação para o Serviço Social ganha o estatuto de elemento constitutivo da própria intervenção profissional.

Essa abordagem contribui significativamente para pensarmos que a dimensão investigativa não se constitui apenas por uma postura profissional, mas integra grande parte das competências e atribuições profissionais. No entanto, se não se constrói essa postura investigativa, referenciada pelos valores ético-políticos do atual projeto profissional, as visitas, os laudos e pareceres terão apenas significados burocráticos, o que reduz, consideravelmente, as possibilidades de garantir os direitos dos usuários.

Essa compreensão nos remete à seguinte questão como objeto de problematização: "Onde a dimensão investigativa vem sendo trabalhada na formação profissional atual do assistente social?" (depoimento, presidente da Abepss, 2013).

Essa pergunta não nega a defesa de que ela deve ser constituinte de tal formação. E não só: entendemos e defendemos que ela deve ser trabalhada como dimensão interventiva, capaz de contribuir para a construção de um conhecimento qualificadamente crítico da realidade, impulsionador das ações profissionais e capaz de sustentar os debates e estratégias dos assistentes sociais na tentativa de garantir os direitos dos usuários.

No entanto, analisar essa proposta envolve reflexões que, tendo por norte seu “dever ser", identifique, compreenda e problematize se ela tem se operacionalizado nos dias atuais e, caso positivo, em que circunstâncias e com qual(is) objetivo(s). 
$\mathrm{Na}$ tentativa de iniciar esse processo de construção de reflexões, optamos por eleger três ângulos que precisam ser estudados e enfrentados no âmbito da formação profissional em Serviço Social, mediante o complexo desafio proposto.

1. O primeiro envolve a análise da sociedade capitalista atual, as implicações para o ensino superior e as determinações nas condições de trabalho dos docentes.

Essa primeira dimensão é fundamental, já que, segundo Netto (2005), a principal conquista do Movimento de Reconceituação do Serviço Social está relacionada ao estatuto intelectual do assistente social, isto é, a capacidade de reivindicar atividades de planejamento para além dos níveis de intervenção microssocial. Isso significa que a reconceituação assentou as bases para formação profissional continuada. "Mas quais as condições de vida e trabalho que os docentes dispõem para fazer da academia um lugar de formação intelectual?" (depoimento, presidente da Abepss, 2013).

Há indicativos de que estamos passando por processos de precarização do ensino superior, como sinalizamos, e, além disso, são crescentes as cobranças e pressões por produtivismo, paralelamente a um trabalho docente intenso, inclusive em fins de semana e feriados. Provavelmente, isso tem contribuído para formação de acadêmicos em Serviço Social, e não de intelectuais, o que, embora tenha importância, não seja suficiente mediante o projeto profissional atual (depoimento, presidente da Abepss, 2013).

2. Um segundo ângulo que nos desafia na atualidade está vinculado ao lugar que a dimensão investigativa tem ocupado na formação profissional do assistente social e como isso tem sido construído nos cursos de graduação em Serviço Social.

A esse respeito, o Serviço Social tem ampliado suas produções científicas e, hegemonicamente, sinalizado que a dimensão investigativa é constituinte da formação profissional do assistente social. Desta forma, é necessário que seja garantida sua horizontalidade ao longo de tal formação. As produções de Iamamoto (1998), Guerra (2009), Martinelli (1999), Mota (2011), Dahmer (2008), Santos (2013), dentre outros, são fundamentais para tal compreensão, além da revista Temporalis (v. 1, n. 25, 2013), com artigos de grande contribuição para o debate da formação profissional. 
No entanto, quando se pensa e se aproxima concretamente da formação profissional atual, torna-se possível identificar uma série de propostas que mais se distanciam do que se aproximam das diretrizes gerais de 1996. Ainda é possível observar a construção de disciplinas de pesquisa que se propõem a ensinar os discentes a se tornar pesquisadores, muitas vezes direcionadas a construção de propostas de trabalho de conclusão de curso. Isso tem contribuído para manter uma cisão instrumental entre construção do conhecimento (desenvolvido na academia) e intervenção profissional (vinculada aos profissionais caracterizados como da "ponta") (depoimento, presidente da Abepss, 2013).

Quando se fala em dimensão investigativa, reporta-se a ela como um "espírito" que o assistente social precisa "encarnar" e, deste modo, realiza-se uma discussão que contribui para o conhecimento acerca de que essa dimensão deve fazer parte do trabalho do assistente social. Mas como essa dimensão deve ser construída? "Por que" e "para quê" o assistente social precisa ter uma postura investigativa?

De forma geral, a tradução das dimensões teórica, ética, política e técnica-operativa como base da dimensão investigativa não tem se processado na formação profissional em Serviço Social. Portanto, o acadêmico em Serviço Social, embora muitas vezes entenda que é preciso ter uma postura investigativa, não tem sido instrumentalizado para sua apropriação como dimensão constitutiva da intervenção profissional.

Neste sentido, ao compreender que a dimensão investigativa deve ser estratégia de conhecimento e intervenção, torna-se urgente que a formação profissional se redirecione para formar assistentes sociais que se apropriem e tenham clareza do "por que", "para quê" e "como" conhecer e, neste caso, não há sobreposição de uma questão em relação à outra.

3. O terceiro ângulo que também precisa ser objeto de estudo e novas problematizações, envolve a necessidade de pensar e propor estratégias de trabalhar a investigação não apenas em relação a uma disciplina específica, mas ao longo de todo o processo de formação profissional do assistente social.

Ao realizar a legítima e insubstituível defesa anterior, não desconsideramos aspectos particulares deste processo. Nesse caso, não podemos negar que o Serviço Social necessita redirecionar seu olhar para os dados numéricos, muitas vezes trabalhados na graduação em disciplina vinculada a estatística. Sabemos e defen- 
demos que a identificação de dados estatísticos não é suficiente, mas precisamos qualificar e trabalhar dados quantitativos no contexto do projeto profissional atual.

Isso significa dizer que ao investigar, sistematizar e produzir dados comprometidos com a realidade e com o projeto de profissão, o assistente social passa a ter a possibilidade de objetivar sua prática profissional e "alimentar práticas profissionais comprometidas com processos emancipatórios" (Bourguignon, 2008, p. 302-303). Ou seja, ele passa a ter, junto à gestão e à instituição de modo geral, um discurso não mais genérico, capaz de conquistar espaço e vencer disputas na defesa dos direitos dos usuários.

Portanto, precisamos, ao longo da formação profissional em Serviço Social, construir estratégias de aproximação do conhecimento e da realidade, desconfiando, questionando, refletindo e problematizando. Neste sentido, entendemos a dimensão investigativa como um processo que precisa ser aguçado e desenvolvido na graduação em Serviço Social, e esse é um compromisso que deve ser assumido, sobretudo, pelos docentes, que mesmo vivenciando diariamente a precarização de suas condições de trabalho, devem assumir e se responsabilizar por esse compromisso teórico, metodológico, ético, político, técnico e operativo na formação de assistentes sociais, seja através de disciplinas ministradas em sala de aula, seja por meio da organização de eventos de cunho científico, bem como de espaços de debates e reflexões críticas.

Caso o discente não desenvolva uma postura inquieta, curiosa, estando disposto a aprender e compreender o inesperado, aquilo que extrapola suas referências e o leva a ir além do absolutamente óbvio, poderá haver uma "cristalização das informações, a estagnação do aprendizado profissional, o que, consequentemente, comprometerá o compromisso do assistente social com a qualidade dos serviços prestados à população usuária" (Fraga, 2010, p. 7). É a respeito dessas questões vinculadas à dimensão investigativa na prática profissional do assistente social que discutiremos na próxima sessão.

\section{0 lugar da dimensão investigativa na prática profissional do assistente social}

A leitura inicial que fazemos dos dados e depoimentos coletados através de pesquisa realizada com assistentes sociais supervisores de estágio na área da 
saúde em instituições situadas nas regiões norte e noroeste do estado do Rio de Janeiro indicam que, assim como na formação profissional, pensar o "lugar" que a dimensão investigativa tem construído na prática profissional do assistente social exige a compreensão da instituição e de suas condições, rotina e dinâmica de trabalho, embora o discurso referente à importância da dimensão investigativa seja hegemônico entre os assistentes sociais entrevistados.

Desta forma, uma primeira indicação geral, independente da instituição de atuação do assistente social, é que a dimensão investigativa proporciona a construção de "subsídios para o profissional pensar e repensar a atuação profissional dele" (assistente social, 2014).

Isso significa que há um discurso crítico, colocado em xeque no contexto de mercantilização da educação superior, mas que tem conseguido sobreviver no interior de algumas universidades e vem sendo reproduzido, majoritariamente, entre os assistentes sociais trabalhadores em diferentes instituições. Assim, foi possível identificar a dimensão investigativa como constitutiva da intervenção profissional de um grupo de assistentes sociais, por intermédio dos seguintes depoimentos dos profissionais entrevistados:

[...] se a gente não conseguir sistematizar as informações, a gente não consegue trabalhar com o paciente. A gente precisa mesmo dos dados, né. Elaborar esses dados, analisar esses dados pra poder a gente ter uma ação, porque se a gente não fizer isso, a gente fica muito no senso comum. Fulano falou isso, ah é e tal, mas eu quero investigar, quero pesquisar, entender o que ele ta querendo dizer. (Depoimento de assistente social, 2014)

No ano de 2013, por exemplo, 30\% dos casos não passaram pelo Serviço Social. O que está acontecendo? Isso é um exemplo prático. Ou levantar lá: ocorreram tantos óbitos esse ano e a maioria foi atendido pelo profissional tal, isso tem alguma relação? Não tem? O que tá acontecendo? E fora os dados que podem estar sendo colocados a nível municipal, estadual para que possam ser pensadas políticas de intervenção. (Depoimento de assistente social, 2014)

Esses depoimentos demonstram a tentativa de construção da dimensão investigativa na prática profissional do assistente social. Esses profissionais realizam seus trabalhos em serviços especializados (CAPS AD e Vigilância 
Epidemiológica do Programa Municipal DST/Aids) através de concurso público, e ora desempenham suas atividades exclusivamente na instituição, ora possuem vínculos empregatícios com outras instituições. Em um desses casos, a dinâmica institucional demanda a produção desses dados para alimentar a política local e/ou estadual, o que é fundamental para sua construção.

No entanto, preliminarmente, ousamos afirmar que, em diversas circunstâncias, esse discurso não se materializa ao longo das intervenções profissionais, o que contribui para construção de práticas com características conservadoras. Essa afirmação pode ser evidenciada ao nos aproximar da realidade hospitalar, caracterizada pelo plantão social, que indicou o distanciamento da dimensão investigativa como dimensão interventiva. Isso não significa que a instituição de trabalho do assistente social seja o único fator determinante da dimensão investigativa como constitutiva da prática profissional.

A esse respeito, é fundamental compreender que a realidade de trabalho profissional é determinada por múltiplas forças e expressões, frutos do ideário, das ações e ataques neoliberais que, muitas vezes, aprisionam os profissionais em suas amarras. Enfrentar o caos expresso na microrrealidade em que se encontra o assistente social vai exigir não apenas um arsenal teórico-metodológico, mas também resistência aos ataques a sua própria intelectualidade e criticidade, bem como, as limitações (re)construídas diariamente pela realidade capitalista, que o desafia a não ser crítico, propositivo e comprometido.

A trama dessa realidade tem contribuído para a falta de protagonismo profissional. Deveria ser o contrário. No entanto, com uma atuação que tem se colocado limitada a políticas e programas sociais precários, o assistente social não tem conquistado notáveis avanços articulados ao projeto ético e político profissional. Mesmo fazendo parte do discurso de muitos assistentes sociais, é possível afirmar que há dúvidas do projeto que esses profissionais têm configurado como "seu" em suas ações.

Vasconcelos (2010-2011, p. 6), acrescenta que estamos falando em profissionais que, ao identificar as demandas presentes na sociedade e refletir a respeito das possibilidades de ação, não estão construindo respostas profissionais capazes de favorecer o protagonismo de diferentes segmentos da classe trabalhadora. 
Portanto, a análise da prática profissional tem indicado uma tensão entre o que se deseja construir com base nas Diretrizes Gerais de 1996 e o que tem se processado na realidade, com justificativas aparentemente associadas a, sobretudo, três elementos: 1) Precarização da formação profissional; 2) Precarização das condições de trabalho; 3) Condição de trabalhador assalariado.

No entanto, ao longo da pesquisa de campo, foi possível identificar um outro elemento presente na fala dos assistentes sociais ao analisarem a realidade do Serviço Social contemporâneo: o não compromisso com a qualidade dos serviços prestados, na perspectiva ético-política profissional atual. Em alguns casos, os depoimentos foram incisivos na falta desse comprometimento, determinado, sobretudo, pela falta de aprimoramento intelectual, na perspectiva da competência profissional (um dos princípios fundamentais do Código de Ética Profissional do Assistente Social, 1993). A esse respeito é preciso destacar:

Encontrei um Serviço Social com a estima no chão. Contribuição muita dos profissionais que permitiram [...]. Profissionais (assistentes sociais) que não se prepararam. 90\% não estão com capacitação para trabalhar como assistentes sociais. (Depoimento de assistente social, coordenadora do Serviço Social de um hospital público, 2014)

Eu acho que Serviço Social deveria se respeitar mais [...]. Eu acho que não leva a sério a profissão. Não é só Serviço Social. É ter um canudo e ponto final [...]. E eu acho que as pessoas não tem essa corresponsabilidade e acaba isso influenciando na prática. E não vão ter respeito ao usuário. Eu vejo muitos profissionais que não respeitam o usuário, pensam que o Serviço Social é um serviço assistencialista, burocrático, que não vai muito além. Por exemplo, muitas pessoas aceitam — "você vai fazer isso, isso e isso" — não querem desafiar, ir além, não quer provocar no sentido de reflexões. (Depoimento de assistente social, 2014)

Como pontuamos no início deste artigo, a educação, na era do capital, é vinculada ao mercado, de forma a atender aos interesses de sua reprodução, sem crítica e reflexão. Desta forma, não se pode negar que, em um contexto de precarização da formação profissional e sérias dificuldades para apropriação e interiorização de criticidade, além de um acesso ao Serviço Social na tentativa, muitas vezes exclusiva, de melhor inserção no mercado de trabalho, muitos 
valores ético-políticos, construídos a partir da "intenção de ruptura" durante o Movimento de Reconceituação, têm perdido a centralidade na prática profissional do assistente social, que de forma geral continua priorizando ações imediatas e fragmentadas, tendo por justificativa predominante sua condição de trabalhador assalariado.

Embora essa condição de assalariado, conforme Iamamoto (2009), estabeleça através das instituições empregadoras, as condições em que esse trabalho se realiza (intensidade, jornada, salário, controle do trabalho, índices de produtividade etc.), é fundamental que o assistente social mantenha uma dupla vinculação no cotidiano de sua prática: com as instâncias mandatárias institucionais e com a população usuária.

E isso requer competência teórico-metodológica para leitura de realidade. Competência fruto da atualização profissional constante e do comprometimento com a prática que se realiza. Esta afirmativa configura um grande desafio interposto aos assistentes sociais, visto que a possível construção do conhecimento no decorrer da prática profissional deve ser acompanhada por reflexões e intervenções capazes de materializar os princípios norteadores do projeto ético e político profissional. E essa proposta vai exigir não apenas o conhecimento de tal projeto, mas também a habilidade do profissional, pois ao deixar de ser um instrumento da instituição empregadora e se colocar na condição de sujeito de suas ações, o profissional rompe com uma "zona de conforto" que vai lhe demandar posicionamentos críticos direcionados a mobilização e ao acesso, com qualidade, dos usuários aos serviços, através das políticas, mas também, a manutenção de seu contrato de trabalho, enquanto trabalhador assalariado (grifo do autor).

Isto significa que, ao optar pela ruptura com práticas conservadoras e tentar ultrapassar o lugar histórico assumido pelo Serviço Social ainda nos dias atuais (o de "instrumento" da instituição empregadora para controlar e manter a ordem institucional), o assistente social faz a opção por uma prática que vai exigir o enfrentamento em um espaço que tem se complexificado e se tornado, a partir das transformações societárias, cada vez mais arenoso, mas que, ao ter consciência da intenção social e ético-política de sua ação, suas bases serão mantidas de forma sólida. 
Estes são desafios complexos, que exigem a mobilização da categoria profissional. Portanto, além de crer e reproduzir, com consciência, o discurso profissional, o assistente social precisa estar mobilizado para transformar a sua prática para além de seu produto. No entanto, essa competência pode estar perdendo espaço para a solução dos problemas como uma solução técnica, profissional e apolítica, referendada por uma concepção de eficácia profissional que se vincula ao número de pessoas atendidas e a solução imediata, aparente e individualizadora das demandas.

A superação desta configuração do trabalho determinado por processos precarizados de inserção profissional no mercado de trabalho, pela configuração das políticas e instituições sociais, condições precárias de trabalho e condição de trabalhador assalariado, supõe o acesso a uma educação para além de fins utilitários, capaz de ser "vivida" plenamente pelos indivíduos (Mészáros, 2005) e, por isso, também capaz de possibilitar a análise "consciente dos processos sociais", a partir de suas determinações sociais, políticas, econômicas e culturais, fundamentais para compreensão da "condição prática" do fenômeno em processo de conhecimento e para a criação de estratégias qualificadas de ação. Aliados a estes elementos, é fundamental que este processo seja motivado pelo comprometimento ético e político profissional, pautado no atual projeto do Serviço Social e projetado pelo sentimento de autorrealização, a partir das novas descobertas e possibilidades de intervenção.

Portanto, assinalamos a possibilidade de aproximação com uma concepção de educação mais ampla e que pode ser estratégica quando desenvolvida na perspectiva emancipadora, quando refinada aos atuais valores ético-políticos do projeto profissional do Serviço Social, não se colocando determinada automaticamente pelos interesses dominantes.

Mediante as considerações apresentadas, finalizamos destacando que, em um contexto de precarização do ensino superior e, consequentemente, da formação profissional do assistente social, além da condição de trabalhador assalariado, que sujeita o profissional de Serviço Social a exigências impostas pelos distintos empregadores, é fundamental que se reforce, no seio da categoria profissional, um movimento de luta e defesa de seu projeto de formação profissional, seja através de suas entidades representativas, com destaque para 
Abepss (Associação Brasileira de Ensino e Pesquisa em Serviço Social), seja entre os próprios profissionais ao atuar em sua microrrealidade. E esse processo de defesa e construção coletiva não poderá se desenvolver sem o constante aprimoramento intelectual e o comprometimento com os serviços prestados a população.

\section{Considerações finais}

Ao longo deste artigo, defendemos uma compreensão de educação ampliada, que se direcione para a capacidade de conhecer, ter ciência do real e transformá-lo de forma consciente. No entanto, também identificamos a incontrolabilidade imanente ao sistema do capital, isto é, a incorrigível necessidade de autoexpansão e de acumulação para a qual se deve produzir e reproduzir continuamente as condições objetivas de sua conservação (Mészáros, 2005).

Mediante essa compreensão e ao ter por base as Diretrizes Gerais de 1996 e construir as problematizações vinculadas à formação profissional, a primeira sessão do artigo identificou três ângulos que desafiam o Serviço Social na atualidade e que, portanto, merecem ser colocados no centro dos debates.

Ainda em relação à formação profissional em Serviço Social atual, indicamos a necessidade de aprofundar as seguintes questões:

1. Qualificar nossos estudos referentes aos processos atuais de precarização do ensino superior e condição de vida e saúde dos discentes e docentes.

2. Redirecionar nossas análises para o ensino à distância, se aproximando de sua metodologia de trabalho.

3. Desenvolver e estreitar as análises referentes à mídia e ao Serviço Social. Isto é, de que forma os discentes e assistentes sociais têm trabalhado com as diversificadas informações processadas, em curto tempo, pela mídia (através do acesso às redes sociais, jornais, televisão e internet de modo geral)? A mídia é utilizada como instrumento de trabalho? Há cariz educativo e político-crítico nas interpretações, análises e uso da mídia como instrumento de trabalho?

Essas análises, na perspectiva crítica, são fundamentais para repensar o lugar da dimensão investigativa na formação profissional em Serviço Social. 
No que se refere à dimensão investigativa na prática profissional, sinalizamos a partir de resultados preliminares de pesquisa que o discurso crítico vinculado à dimensão investigativa e sobrevivente no cenário atual não tem conseguido se traduzir na prática profissional do assistente social que, segundo Vasconcelos (2010-2011), continua mantendo características conservadoras. Além disso, identificamos, a partir de análise teórica e empírica, que essa situação tem sido determinada por quatro elementos centrais.

Ainda em relação à prática profissional de forma ampliada, reforçamos a necessidade de aprofundar os estudos referentes aos seguintes elementos:

1. Investir em estudos e pesquisas que busquem desvendar e aprofundar as análises vinculadas aos determinantes da prática profissional caracterizada como conservadora nos dias atuais;

2. Investir na aproximação do cotidiano de trabalho do assistente social nos diferentes espaços de atuação, de maneira contínua, superando pesquisas e estudos baseados em técnicas pontuais de conhecimento da realidade;

3. Investir no estágio supervisionado em Serviço Social como um espaço capaz de possibilitar uma relação de troca entre supervisores/aluno, supervisores/supervisores, que deverá contribuir para formação do discente, a análise de realidade, reflexão e problematização da prática profissional, capazes de embasar a construção e reconstrução diária de tal prática, através da educação permanente;

4. Investir na universidade enquanto espaço aberto para o debate sobre a prática profissional, por meio de cursos, palestras que superem uma relação de poder entre quem transmite e aquele que recebe informações/conhecimento, mas espaço que garanta a construção coletiva;

5. Colocar-se aberto para o debate teórico-metodológico e ético-político existente no interior da categoria profissional na atualidade. É através da garantia de espaços democráticos de debates, escuta, troca de experiências que se poderá reforçar, no interior da categoria, os valores de sociedade que queremos. (Moraes, 2014, p. 15)

Mais que isso: precisamos voltar a estudar a prática profissional do assistente social, compreendendo-a em uma estreita relação com a formação profissional. Diante disso, sinalizamos que mais que um artigo que constrói respostas 
referentes às problemáticas analisadas, ele demonstra a inquietação e a necessidade de aproximação com diferentes variáveis inerentes à dimensão investigativa na formação e prática profissional do assistente social, tentando aguçar o leitor a análises dessa situação no cenário brasileiro e na particularidade de sua instituição de trabalho.

Por ora, finalizamos o artigo com a seguinte conclusão preliminar: há indicativos de que a dimensão investigativa se faz presente em parte do trabalho construído por alguns assistentes sociais, no entanto, sem a compreensão da complexidade vinculada à individualidade, sendo restrita a tentativa de abordagem da situação singular e a construção de estratégias de ação imediatas e individualizadas.

Recebido em: 14/8/2014 - Aprovado em: 10/3/2015

\section{Referências bibliográficas}

ABEPSS. Diretrizes gerais para o curso de Serviço Social - 1996. Disponível em: $<$ http://www.abepss.org.br/briefing/graduacao/Lei_de_Diretrizes_Curriculares $>$. Acesso em: 11 nov. 2011.

ABREU, M. M. A formação profissional e o fortalecimento do Serviço Social como área de conhecimento: estratégias e desafios da Abepss no biênio 2007-2008. Temporalis, Brasília, ano 11, n. 22, p. 67-80, jul./dez. 2011.

. A experiência da "Abepss itinerante": a atualidade do projeto de formação profissional frente à contrarreforma da educação. Temporalis, Brasília, ano 13, n. 25, p. 113-132, jan./jun. 2013.

BOURGUIGNON, J. A. A particularidade histórica da pesquisa no Serviço Social. São Paulo: Veras Editora; Ponta Grossa: Ed. da UEPG, 2008.

BRECHT, B. Disponível em: <www.uff.br/revistacontracultura/manifestocontracultura>. Acesso em: 23 abr. 2014.

DAHMER, Larissa. Mercantilização do ensino superior, educação à distância e Serviço Social. Temporalis, Brasília, ano 7, n. 15, 2008. 
FRAGA, C. K. A atitude investigativa no trabalho do assistente social. Serviço Social \& Sociedade, São Paulo, n. 101, jan./mar. 2010.

GUERRA, Y. A dimensão investigativa no exercício profissional. In: CFESS/ABEPSS. Serviço Social: direitos sociais e competências profissionais. Brasília: CFESS/Abepss, 2009. p. 701-718.

IAMAMOTO, M. V. Ensino e pesquisa no Serviço Social: desafios na construção de um projeto e formação profissional. Caderno Abess, n. 8, São Paulo, 1998.

. Serviço Social em tempo de capital fetiche: capital financeiro, trabalho e questão social. 2. ed. São Paulo: Cortez, 2008.

. O Serviço Social na cena contemporânea. In: . Serviço Social: direitos sociais e competências profissionais. Brasília: Cefess/Abepss, 2009. p. 15-50.

. Formação profissional na consolidação do projeto ético-político do Serviço Social brasileiro: fundamentos, resistências e desafios conjunturais. In: SEMINÁRIO ANUAL DE SERVIÇO SOCIAL, 7., 12 maio 2014, Cortez Editora (Org.). Teatro Tuca/ PUC-SP, São Paulo. Disponível em: <https://www.youtube.com/watch?v= zDOnXgCH_1Y>. Acesso em: 11 nov. 2014.

LIMA, Katia. Contrarreforma da educação superior e formação profissional em Serviço Social. Temporalis, Brasília, ano 8, n. 15, 2008.

LIMA, K. R. de S.; PEREIRA, L. D. Contrarreforma na educação superior brasileira: impactos na formação profissional em Serviço Social. Sociedade em Debate, Pelotas, v. 15, n. 1, p. 31-50, jan./jun. 2009.

MARTINELLI, M. L. (Org.). Pesquisa qualitativa: um instigante desafio. São Paulo: Veras, 1999.

MAURIEL, A. P.; GUEDES, O. de S. Desafios da pesquisa na formação profissional do assistente social: um olhar a partir da experiência do curso Abepss Itinerante. Temporalis, Brasília, ano 13, n. 25, p. 13-32, jan./jun. 2013.

MÉSZARÓS, I. A educação para além do capital. São Paulo: Boitempo, 2005.

MORAES, C. A. de S. De que prática profissional em Serviço Social estamos falando? Algumas aproximações teóricas. In: ENCONTRO INTERNACIONAL, 2., e ENCONTRO NACIONAL DE POLÍTICA SOCIAL, 9., Lutas sociais no capitalismo contemporâneo, Vitória: Universidade Federal do Espírito Santo, 4-8 ago. 2014. 
MOTA, A. E. Os desafios da formação profissional na gestão 2005-2006. Temporalis, Brasília, ano 11, n. 22, p. 59-66, jul./dez. 2011.

NETTO, J. P. O movimento de reconceituação 40 anos depois. Serviço Social \& Sociedade, São Paulo, n. 84, p. 5-20, nov. 2005.

PEREIRA, L. D.; ALMEIDA; NEY, L. T. Serviço Social e educação. Rio de Janeiro: Lumen Juris, 2012. (Col. Nova de Serviço Social.)

SANTOS, C. M. dos; PINI, F. A transversalidade do ensino da prática na formação profissional do assistente social e o projeto Abepss Itinerante. Temporalis, Brasília, ano 13, n. 25, p. 133-153, jan./jun. 2013.

VASCONCELOS, A. M. O trabalho do assistente social e o projeto hegemônico no debate profissional. Programa de Capacitação Continuada para Assistentes Sociais, Módulo 4. Brasília, CFESS/Abepss/Cead/UnB, 2000.

. A prática do Serviço Social: eixo de análise. Material didático instrucional. Rio de Janeiro: FSS/UERJ, versão 2010-2011. 